\title{
Application and Development of the Culture of Era in the Design of Fashion Clothing Pattern
}

\author{
Xuesong Yang ${ }^{1, \text { a }}$ \\ ${ }^{1}$ College of Humanities and Sciences of Northeast Normal University, Changchun City, Jilin \\ Province, China, 130000 \\ a597015938@qq.com
}

Keywords: The culture of era; Popular clothing; Pattern design

\begin{abstract}
The culture of era as a representative of a particular era, with distinct characteristics, expressed through different arts. Among them, the application in the popular clothing design is very obvious. The development of the times, and constantly promote the continuous development of various types of design, the impact of the culture of era also provides a particular era of design for more elements. Fashion clothing becomes popular, precisely because of the use of the design patterns, in line with the characteristics of the times, to meet the needs of the market, with a certain distinctive characteristics. This paper will make relative introduction to changes of the culture of era in the pattern design of popular fashion.
\end{abstract}

\section{Introduction}

China has a very long history and culture, experiencing 5,000 years of ups and downs. But also China's unique culture and aesthetic were formed. While at the same time, by the impact of traditional feudal ideas, modern Chinese clothing have a very serious elements of the conservative in the early design. Therefore, the forefront of fashion design specifically were from abroad, with the establishment of new China, and the reform and opening up policy changing China, China's fashion design slowly began to learn from, develop, and gradually increased the unique characteristics of Chinese fashion element. The use of the relevant patterns reflect a certain culture of era, but also received the favor of the market. Whatever the development of any industry, it can't be inseparable from the large political and economic background, a distinctive feature of the times will be displayed through the relevant industries in the era of culture [1]. Researching on the application and development of popular culture in the design of popular fashion design, not only can explore the different times of fashion ideas, but also have a better understanding of history. The reason why the history has been able to be recorded in the history is that the descendants know something worth memorable, some things worth remembering, some things give us some profound lessons. All industries are the same, only having a deep understanding of the past, you can look forward to the future.

\section{The Connotation of the Culture of Era and the Application of Patterns in the Popular Clothing Design}

The Connotation of the Culture of Era. The content of the culture is very rich, whether it is ancient or modern, things with valuable artistic sense can be called culture. But the scope of the culture of era is more accurate, as a culture of the times, there must be a dazzling feature of the times, regardless of the good or bad, those worthy of generations to memorize with the times together can be regarded as the culture of era [2].

The Meaning of Pattern and its Application in Fashion Design. Broadly speaking, the pattern is the drawing painted the substance in the design of the artifacts of the pattern and the design; narrow pattern refers to the application in the design of the texture and color. In the costume design, the design of the pattern refers to the pattern in the narrow sense.

It is often possible to treat the pattern as an painting form, or even an art form. The role of the pattern is usually used as ornament, some patterns have some special man-made role with some 
practical value. Generally speaking, the pattern has three attributes, namely, material field applicability, spiritual field decoration and commodity economy [3]. The application value is the root cause of goods as a commodity, which is said that the practical, the development of the times promotes changes of people's aesthetic, and decoration has become another important role in the pattern, the cost of goods will become an important influencing factor of design, which is another important feature of pattern attributes. It is a very common way of using the pattern in apparel, can be showed up in front of people intuitively, to facilitate the appreciation and the purchase. Usually in the clothing design, clothing parts, clothing structure and clothing styles need to be coordinated.

Clothing Parts and Patterns. Applying the pattern to the neck, chest, waist, abdomen, buttocks, back, arm, elbow, leg, knee and other parts of the overall dress can play a very good decorative effect, thereby enhancing the personality of clothing expressive, the specific location of the specific pattern can make the whole clothing eye-catching, but also highlight the design structure of clothing [4]. In the selection of patterns on the decoration, the use of specific parts of the pattern will be related to the characteristics of the times, while the reference to the three important attributes of the pattern is also very important.

The parts of the chest and the back will occupy a large area of fabric in the traditional clothing, so it provides a large area for the decoration of the pattern. But these two parts are more prominent, but also the clothing parts attaching more attention, therefore, with a little careless, the whole design will appear unexpected [5]. But the specific patterns designed with a decent pattern of embellishment according to different occasions, will play an unexpected artistic effect.

Buttocks, elbows, knees, these parts generally will not use too many patterns to decorate in the process of the traditional design, and the basic design is the same color and texture with the whole clothes. But the development of the times makes people realize the practical value of the pattern, because the wear and tear of these parts are more serious than other parts, so using different fabrics or patterns to modify will make the whole clothes become more durable, which reflects the practicality of the pattern. At the same time, the outstanding design of practicality is another important manifestation of the progress of the times. Thus it stimulates the market, getting more consumers.

Effected by the visual impact, decorative patterns in the waist and abdomen use the most skills in the design. Waist and abdomen can best reflect the proportion and shape effect of clothing body. Usually, if you can not grasp the key point, you can use the traditional way of conservative design, but for the design of the dress, you can decorate waist and abdomen with exquisite pattern, to create a better physical effect.

Clothing Structure and Pattern. Clothing structure will be added the relevant elements of the pattern in the design of the time sometimes. Pattern design of the neckline and pocket in clothing edge brings the whole clothing freshness, while the pattern with different elements of the era make clothing full of certain characteristics of the times, then more easily accepted by the entire market [6]. At the same time, the application of patterns will also have different effects due to the impact of clothing structure, improving the overall style, highlighting the characteristics of clothing, can be achieved in this process.

Clothing Styles and Patterns. Clothing style and pattern have always been combined with each other, complement with each other. The different culture of the times give the clothing not the same style, embellishment for clothing by pattern will change the overall impression of the entire clothing. Using patterns with obvious characteristics of the times to decorate the clothes, not only eye-catching, there is a special meaning of era. And the design of ordinary fashion in the use of patterns will have a style of change, so as to increase the market more choices.

\section{The Application Process of the Era of Culture in the Popular Clothing Design}

In the 1960s, children affected by World War II began to grow, and because of the influence of war, these people demand ideological emancipation, feminism and hip-hop style. Received the impact of the times, the dress pattern slowly emancipated the mind, break through the confinement, with obvious characteristics of the times. In addition, because of the influence of feminism, the 
costumes began to reflect dress with no gender but neutral patterns. At this time of culture of the era is free, unrestrained, urgently need to liberate, and this appeal was also reflected in the design of the clothing pattern [7]. And China was at the end of the civil war soon, more advocating the green uniform, which is determined by the characteristics of the times and the culture of the times.

Later, due to the development of dyeing and printing technology, the fabric design of the clothes had also been further developed, the voice of freedom was growing in the world. The star photos and movie posters began to appear in the clothing design, which is all the rage of the fashion design, and after that, the film posters were used in the design of clothing echoes. At this point, the pattern slowly become diversified under the influence of the era of culture.

In the 1970s, the United Kingdom experienced a massive economic crisis, the domestic social situation was declining, people living is difficult. At this point, there is a large-scale movement punk movement. The sport made punk music for the precondition, greatly promoted a kind of extreme destruction spirit. And this spirit was the essence of this movement, effected by the mainstream of this era of culture, in the clothing design, using punk-style elements further spread this idea as shown in Fig. 1, at the same time, the birth of this anti-rock music has become a popular music in an important style [8]. The spirit of fashion design expressed through the era of cultural elements, which is a direct form of expression for the people.

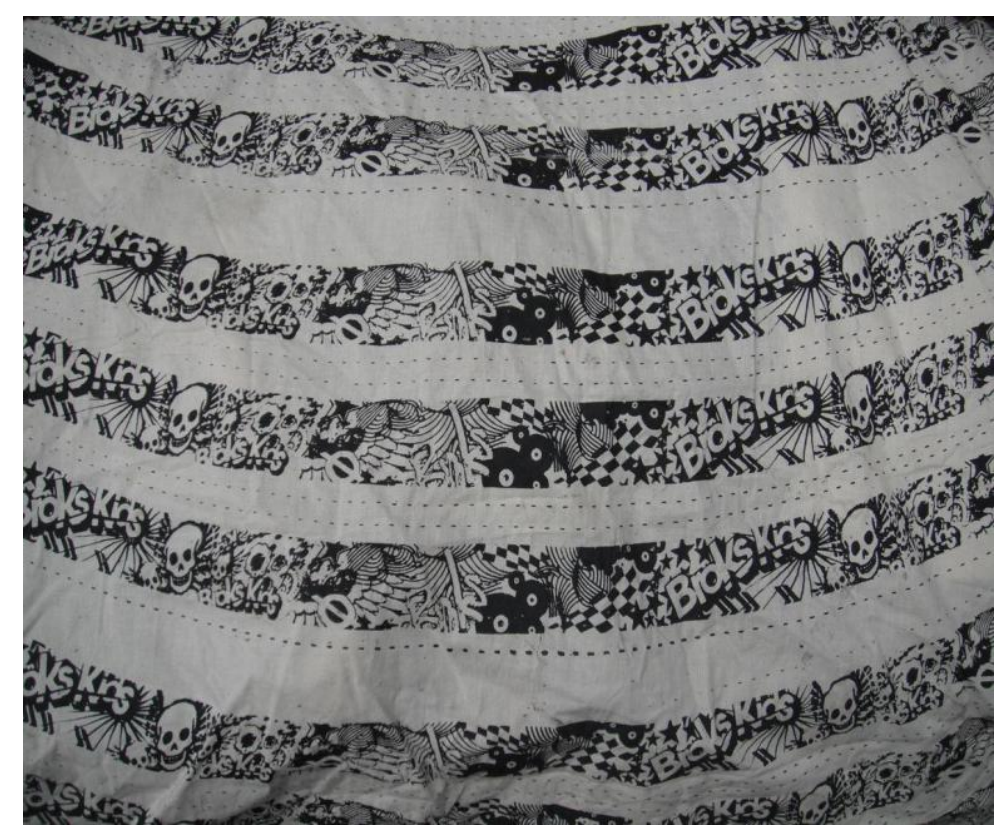

Figure 1. Clothes with punk style

Time flowed to the 90s of last century, by the impact of reform and opening up policy, various industries in China began to open the door and face the world. The garment industry was no exception, more free elements were added in the costume design, compared with the official uniform with the same color and the conservative styles showing more freedom of liberation in seventy or eighty years, at this time culture is the big event of reform and opening up. Facts also had proved that this great initiative not only made a foundation for the rapid rising of comprehensively national strength in the following, but also subtly guided the various industries towards a better direction. At this time, China's design for the clothing had also taken a more striking pattern of text design, therein, design words of short-sleeved and cultural shirt began to convey the heart voices of designer and the majority of young people, that is an open wind and hope. Different from the foreign punk style, the words of our cultural shirt are spread to a real voice, mostly positive or realistic pattern, which is due to the culture in different times led to such differences.

After entering into the 21st century, China's economy has developed rapidly and all walks of life have flourished. Peaceful and stable environment of domestic and world make China get a better 
recuperate. Until the 911 incident occurred, it sounded the alarm to the world's security work. Countries can do more work together to maintain world peace and stability in the subsequent anti-terrorism work. At this time, in order to remember this painful lesson, different words began to appear as a kind of era elements in the clothing design, as shown in Fig. 2. It also declares to the whole world that the time of terrorist attacks has a major harm and seriously endangers for the peace and stability of the world [9]. This kind of culture of era was applied to the clothing, eye-catching patterns at any time told us that we should strengthen the anti-terrorism work, to maintain the hard-won peace.

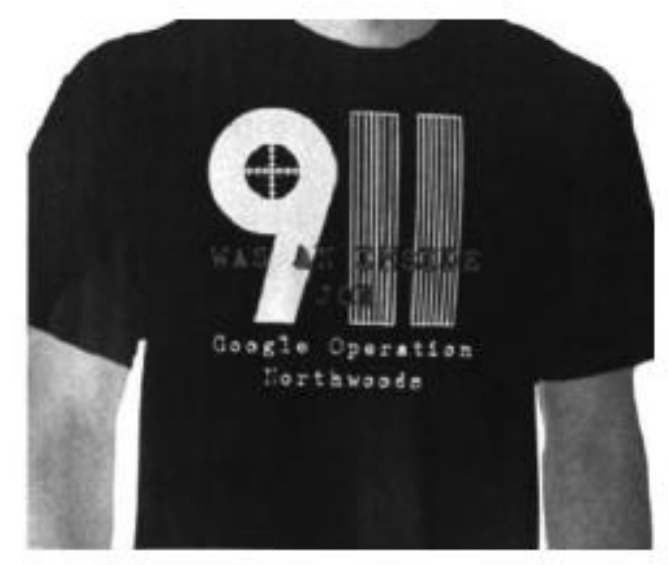

Figure 2. the costume for memorable 911 event

With the success to sponsor the Olympic, China ushered an important year for the Olympic Games in 2008. This was also the first time since China's reform and opening up, China showed his whole development to the eyes of friends around the world, which has important practical significance for future cooperation with countries. At this point, in order to highlight the importance of this culture of era, Olympic rings and Fuwa design were began to be applied in the design of the clothing design, to commemorate this great event, as shown in Fig. 3. Without expectation, this time of the Olympic Games obtained great success, a number of industries including China's tourism industry have brought greater opportunities for development. China is further moving towards the world. Driving by force of this era of culture, application of Olympic elements in fashion design can better meet the entire market, while the costume design related to the Olympic Games also has a strong commemorative significance.

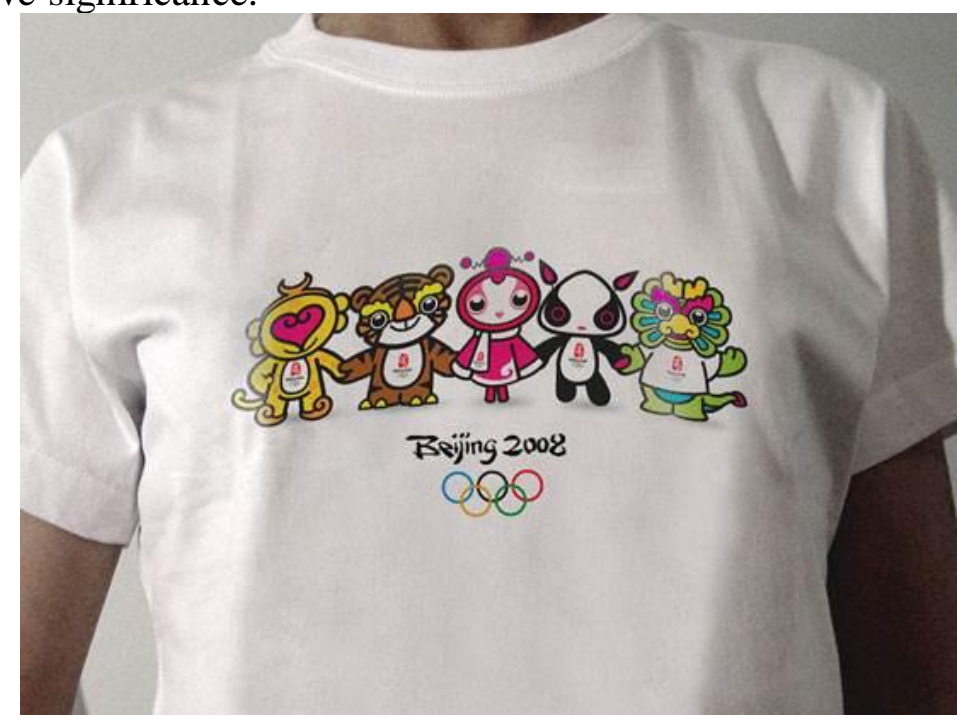

Figure 3. T-shirt with Olympic style

After the Olympic Games, China's overall national strength continued to rise, China needs to better show themselves to the world. The domestic costume design focuses on high-end European 
style and more freedom of personality design. At this time, the domestic development is stable, by the co-action of the Japanese and Korean style and the European fashion, China's domestic clothing design has become very diverse, the themes and elements used by the world's clothing design are more novel, retro pattern, Combined with the natural design, are derived from the background of the green and healthy development, the pursuit of individual liberation. In China's unique fashion design, traditional Chinese cultural elements began to be followed. The use of flat patterns in clothing has already had a long history. Put China's ink painting, landscape painting and representative elements showing the good mountains and rivers into the clothing design, to show the new look of China in the world [10]. At the same time the use of embroidery patterns more prominent ancient and cultural heritage of the design style, as shown in Fig. 4. This style is better able to show China's outstanding traditional culture. The Chinese style design style should not only be China's cheongsam design, it should also include the use of Chinese elements with obvious meaning.

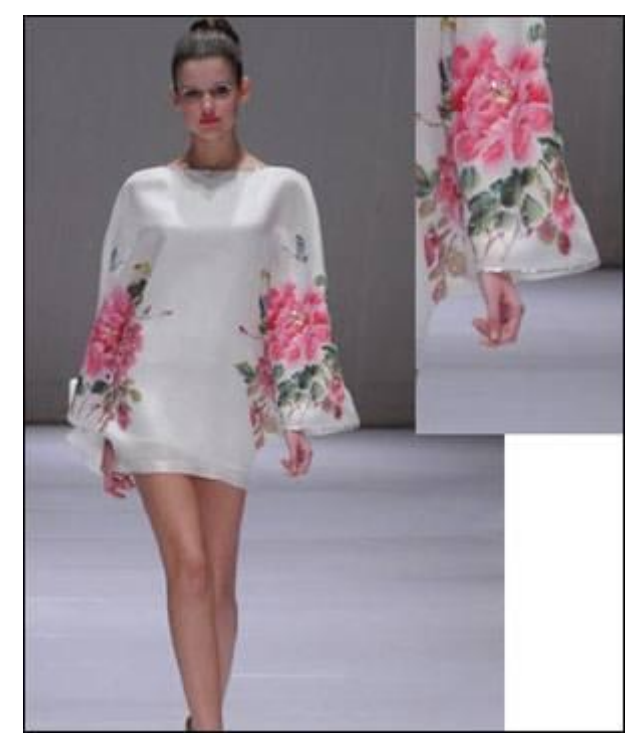

Figure 4. Embroidery dress

\section{Conclusion}

The costume is presented as designed into an art, is the desire of every fashion designer. The clever use of the pattern will help to achieve this goal. Patterns design with the era branded will not only give a refreshing feeling, at the same time, these patterns are a symbol of the times. In the fashion design, adding the era of cultural elements is a big trend, can not be avoided. China's fashion design still have a lot of shortcomings, mainly in the aspects that pursuing fashion leads to too many kinds of styles, and update too fast, the lack of practical value of the content; lack of personalized, by common impact of Japanese and Korean culture and the European fashion, copy action of China's clothing design is too serious, it is difficult to reflect their own characteristics; the use of regional culture is too scarce. In fact, China's traditional culture is rich, there are many elements of design with Chinese characteristics, coupled with the big family of 56 ethnic groups in China, different ethnic patterns are worth learning from. This will not only help to form China's unique fashion design road, but also better inherit the heritage of traditional Chinese culture in the era of culture.

\section{References}

[1] Liu Baoyao. Effect of Chinese traditional auspicious patterns on the modern costume design [J]. Modern decoration (theory) .2016 (8): 108-109. 
[2] Liang Huier, Yang Ren, Tan Ying, et al. The application of traditional brushwork figure in the design of middle-aged and elderly clothing [J]. Silk. 2016 (8): 60-65.

[3] Yang Ren. Fu Shaohai, Tan Ying, et al. Middle and old women's pattern design and its development trend [J]. Journal of Textile Research, 2016 (10): 107-112.

[4] Jiang Meizhen. Discussion On the use of fashion elements of modern clothing patterns [J]. Art Literature, 2014 (1): 185,191.

[5] Qiu JiaLi, Wang Qian. Brief analysis of paper-cut pattern in the use of women's design [J]. Modern Decoration (theory), 2014 (6): 84-85.

[6] Zhang Yue. The application and innovation of Chinese traditional design in modern women dress design [J]. Art Technology, 2014 (6): 123,186.

[7] Peng Jing. The application of Chinese traditional patterns in the use of modern costume design [J]. Artists, 2013, S1: 149-151.

[8] Yu Ying. Discussion on the use of patterns in costume design [J]. Journal of Hubei Institute of Science and Technology, 2013 (3): 133-134.

[9] Zhang Fuliang. Costume pattern [M]. Shanghai People's Fine Arts Publishing House. March 2008.

[10] Liu Guolian. Full concept guide of Costumes [M]. China Textile Publishing House. July 2009. 